\title{
Batch and Column Adsorption of BOD and COD in vegetable oil industry effluents Using Activated Carbon from Fluted Pumpkin (Telfairia, Occidentalis. Hook. F) Seed Shell
}

\author{
Verla Andrew Wirnkor ${ }^{1, \star}$, Briggs Olulu Amonia ${ }^{1}$, Verla Evelyn Ngozi ${ }^{2}$ \\ ${ }^{1}$ Department of Pure and Industrial Chemistry, College of Natural \& Applied Sciences, \\ University of Port Harcourt, P. M. B. 5323, Port Harcourt, Nigeria \\ *Phone: +23476988937 \\ 2Department of Environmental Technology, School of Environmental Technology, \\ Federal University of Technology, Owerri, Imo State, Nigeria \\ *E-mail address: verngo@yahoo.com
}

\begin{abstract}
The use of waste to reduce pollution has been advocated by many researchers. In this study five samples of physically prepared fluted pumpkin seed shell activated carbons (PFACs) prepared elsewhere were successfully used in reducing Biochemical oxygen demand (BOD) and chemical oxygen demand (COD) of vegetable oil industry effluents (VOIE). BOD readings of effluent were measured using the Lovibon BOD IR Sensomat while COD was determined by use of PCcheckit COD Vario (Lovibond) consisting of PCcheckit COD Vario photometer and COD reactor ET 108 model. Batch adsorption had better performance (BOD and COD removal of $52 \%$ to $83 \%$ ) over column adsorption $\left(\mathrm{BOD}_{5}\right.$ and $\mathrm{COD}$ removal of $35 \%$ to $\left.86 \%\right)$. Batch adsorption gave better BOD and COD reduction. Though $\mathrm{BOD}$ and $\mathrm{COD}$ removal varied widely with carbon dose, $\mathrm{pH}$, temperature and contact time the effects of theses factors investigated in the reduction of BOD and COD were complex and difficult to streamlined.
\end{abstract}

Keywords: Batch; Column; Removal; Vegetable oil; Effluents; Adsorption

\section{INTRODUCTION}

When discharged into the environment the deleterious effects of vegetable oil industry effluents are significant due to high Biochemical oxygen demand (BOD) and Chemical oxygen demand (COD) [1-3]. These two parameters reflect the organic content of the effluent and thus its oxygen consumption which is factor militating against aquatic life. In most third world countries including Nigeria industry effluents are discharged directly into water bodies usually without any form of treatment.

Production of refined vegetable oil involves many technological processes such as pretreatment of oilseeds, refining and modification of oils [4]. These processes require large volumes of water and since the end product does not contain water, waste water commonly called effluent is usually much. The effluent mainly comes from degumming, deacidification and deodorization steps [5] which are part of refining process. Acid splitting is also part of 
refining process in which sulphoric acid is added to the soap stock causing free fatty acids to be separated from the medium.

The resulting effluent is highly acidic. The composition of VOIE may vary widely from day to day depending on operating conditions, type and source of oil processed. As a result of complexity of wastewater and variations in quantity and characteristic, the choice of wastewater treatment methods depends on many local conditions [6].

Many authors have discussed physical methods like ultra filtration [7] and reverse osmosis [8] in the treatment of waste water. Physicochemical methods which includes precipitation, coagulation, flocculation and flotation $[7,9,10]$ have also been investigated. These have major drawback in their cost and efficiency and so physicochemical methods followed by biological processes [11-13] biological methods [14] and other methods like thermo chemical treatment [15] and photocatalysis [16] for oily wastewater treatment have equally revealed encouraging results. Adsorption technology is considered to be the most effective and proven technology with wide potential applications in both water and wastewater treatment $[17,18]$. Adsorption hold promise in the treatment of wastewater, as it is convenient, easily operable and simply designed. Sorption is a rapid phenomenon of passive sequestration of sorbet from an aqueous or gaseous phase onto a solid phase [19]. For the removal of pollutants, generally sorbents with high surface area are preferred. Activated carbon has been found to be a versatile sorbent, however its use is being equally limited because of its high cost. As such efforts have been directed towards developing low-cost alternative sorbents form locally sourced materials and vast amount of literature exist [20]. However, studies on the reduction of BOD and COD of vegetable industry effluents are not available to our knowledge. The present paper was therefore to evaluate the possible use of locally produced activated carbon in reducing BOD and COD from vegetable oil industry effluents.

\section{MATERIALS AND METHODS}

The $\mathrm{pH}$ and conductivity were determined according to the method of ASTM D3838-80 with slight modification as follows; $1.0 \mathrm{~g}$ of each carbon was weighed and transferred into a $250 \mathrm{ml}$ beaker and $100 \mathrm{ml}$ of distilled water was added and stirred for 1 hour. Samples were allowed to stabilize and then $\mathrm{pH}$ measured using an electronic $\mathrm{pH} /$ Conductivity meter, Jenway 430 Model. The same samples were further used for electrical conductivity (EC) of the $\mathrm{AC}_{\mathrm{S}}$ and results read off in $\mu \mathrm{S}$ [21].

TDS was determined using the electrical conductivity method in which after calibrating the meter with $1000 \mu \mathrm{S} / \mathrm{cm}$ standard the TDS mode key was pressed. The probe was again rinsed with some portion of VOIE sample before immersing into sample. The reading displayed was allowed to stabilize before salinity readings were recorded.

All BOD readings of effluent were measured using the Lovibon BOD IR Sensomat. A $10 \mathrm{ml}$ sample volume was collected into the $500 \mathrm{ml}$ BOD flask. The IR-pressure sensor was connected to the BOD flask and the start button on the Sensomate depressed. Then the IR sensor was logged into the BOD-Sensomat and reading converted directly to $\mathrm{mg} / \mathrm{l}$ of BOD and BOD value read and recorded. COD was determined by use of PCcheckit COD Vario (Lovibond,Germany) consisting of PCcheckit COD Vario photometer and COD reactor ET 108. Briefly, $20 \mathrm{ml}$ effluent sample was put into contact with the acid solution that then held at $148^{\circ} \mathrm{C}$ for $2 \mathrm{hr}$. After coning the sample was then placed into sample cell of the PCcheckit 
COD Vario photometer. The colour of the samples varied from orange to dark green indicating the COD value of the range $15-3800 \mathrm{mg} / \mathrm{l}$.

\section{1. BOD and COD variation with contact time}

$50 \mathrm{mls}$ of VOIE of BODi and CODi were taken into five conical flasks and $1 \mathrm{gs}$ of various PFAC was added and agitated at various time periods of 1, 2, 3, 4, 5 and $6 \mathrm{hrs}$ respective. The solutions were filtered through Whatman no 41, and then centrifuged at 1000 rpm for 5 mins, decanted and their BODs and CODs read off with use of a digital BOD manometer model.

\section{2. BOD and COD variation with carbon dose}

This was carried out according to [22,23] with modifications. Briefly, various mass of PFAC in grams from $0.5,1,1.5,2,2.5$ and 3 were weighed and transferred into $250 \mathrm{mls}$ conical flask. VOIE of BODi and CODi were placed into the conical flask. The flask were tightly stopped with aluminium foil and agitated for $1 \mathrm{hr}$ by centrifugation at $1000 \mathrm{rpm}$ for 5mins, allowed to settle, decanted and filtered with Whatman no. 41. The BOD and COD of filtered samples were measured. This procedure was repeated using $\mathrm{FAC}_{1}$ to $\mathrm{FAC}_{5}$.

\subsection{BOD and COD variation with $\mathrm{pH}$ in batch Experiment}

$50 \mathrm{mls}$ of VOIE with a known BOD and COD and respectively were place in five conical flask in which five $1 \mathrm{gms}$ of PFAC have been previously weighed and placed. The $\mathrm{pHs}$ of the solutions were adjusted with $0.5 \mathrm{~m} \mathrm{HCl}$ and $0.1 \mathrm{~m} \mathrm{NaOH}$ solutions to obtain pHs of 2, $4,6,8,10,12$ respectively. The solutions adjusted $\mathrm{pHs}$ were then tightly covered with aluminium foil and agitated. At the expiration of $1 \mathrm{hr}$ the solutions were filtered using Whatman No 41 centrifugation at $1000 \mathrm{rpm}$ for $10 \mathrm{mins}$, decanted and BOD and COD in turns read with a digital BOD manometer.

\section{4. BOD and COD variation with temperature using $1 \mathrm{~g}$ of PFAC}

$50 \mathrm{mls}$ of VOIE with $\mathrm{BOD}_{\mathrm{i}}$ and $\mathrm{COD}_{\mathrm{i}}$ were measured into five $250 \mathrm{mls}$ conical flask in which 1 gs of PFAC were previously weighed and placed. The conical flask labelled 10, 20, $30,40,50,60$ and 70 degrees centigrade. The flasks were properly covered using aluminium foil, agitated with hand for 2 mins and heated on a thermostatic water bath to their appropriate temperatures. The solutions were centrifuged at $1000 \mathrm{rpm}$ for $5 \mathrm{mins}$, decanted and then BOD and COD values read using a BOD and COD manometer model.

\section{RESULTS AND DISCUSSION}

\section{1. Nature of adsorbents}

Adsorbents used in this work were prepared elsewhere according to [24]. They were called physically prepared fluted pumpkin activated carbon (PFACs) and were characterized using standard methods. Table1 shows some physico-chemical parameters of vegetable oil industry effluents (VOIE) used. Major characteristics exhibited variations and complexity and have been fully discussed [20]. Vegetable oil industry effluents are an acidic complex aqueous media composed of widely-distributed organic and inorganic materials dissolved as well as suspended in water. The organic contaminants lead to high BOD and COD. 
Table 1. Physico-chemical parameters of palm oil mill effluents.

\begin{tabular}{|c|c|c|c|}
\hline Parameters & $\begin{array}{c}\text { Mean } \pm \text { SD } \\
(\mathrm{mg} / \mathrm{l})\end{array}$ & WHO & Comment \\
\hline Temperature & $27 \pm 0.01$ & - & - \\
\hline $\mathrm{pH}$ & $4.67 \pm 0.015$ & $6-9$ & Acidic effluent \\
\hline Cond. $(\mu \mathrm{S} / \mathrm{cm})$ & $253 \pm 1.15$ & - & - \\
\hline $\mathrm{Sal}(\%)$ & $625 \pm 4.50$ & 600 & Above standard \\
\hline TDS (mg/l) & $127.7 \pm 5.77$ & 2000 & Above standard \\
\hline TSS (mg/l) & $563.6 \pm 3.15$ & $30-50$ & Above standard \\
\hline BOD (mg/l) & $347 \mathrm{I} .83 \pm 1.70$ & 50 at $20^{\circ} \mathrm{C}$ & Above standard \\
\hline $\begin{array}{c}\text { Permanaganate } \\
\text { value }\end{array}$ & $16.28 \pm 5.50$ & - & - \\
\hline TOC (mg/l) & $3851.37 \pm 4.41$ & - & - \\
\hline COD (mg/l) & $3959 \pm 3.82$ & 250 & Above standard \\
\hline Sulphates (mg/l) & $684 \pm 5.60$ & - & - \\
\hline Phosphates (mg/l) & $890 \pm 3.50$ & - & - \\
\hline
\end{tabular}

Batch and column experiments were conducted and the physicochemical characteristics of effluent measured for each activated carbon sample coded $\mathrm{FAC}_{1}, \mathrm{FAC}_{2}, \mathrm{FAC}_{3}, \mathrm{FAC}_{4}$ and $\mathrm{FAC}_{5}$.

\section{2. Resistance factors and removal efficiency of vegetable industry effluents}

The resistance factors determined were: change in biochemical oxygen demand $(\triangle \mathrm{BOD})$ and chemical oxygen demand $\triangle \mathrm{COD}$, and ratios of BOD/COD for each carbon sample after adsorption for an equilibrium period of six hours [25]. Percent BOD and COD were calculated from equation 1

$$
\% B O D r=\frac{B O D i-B O D f}{B O D i} \times 100 \ldots \ldots \ldots 1
$$


were $\%$ BODr is percent BOD reduction, BODi and BODf are initial and final BOD values respectively. A similar expression for COD can be written.

Table 2. Resistance factors of VOIE after adsorption for batch and column systems.

\begin{tabular}{|c|c|c|c|c|c|}
\hline & $\Delta$ BOD & $\Delta$ COD & $\%$ BOD & $\%$ COD & BOD $/ C O D$ \\
\hline \multirow{2}{*}{$\begin{array}{c}\text { FAC1 Batch } \\
\text { Column }\end{array}$} & 2611 & 1507 & 75 & 79 & 0.24 \\
\cline { 2 - 6 } & $\mathrm{C} 2701$ & 4410 & 78 & 61 & 0.28 \\
\hline \multirow{2}{*}{$\begin{array}{c}\text { FAC2 Batch } \\
\text { Column }\end{array}$} & $\mathrm{B} 1146$ & 1187 & 61 & 67 & 0.29 \\
\cline { 2 - 6 } & $\mathrm{C} 1180$ & 1270 & 63 & 35 & 0.29 \\
\hline \multirow{2}{*}{$\begin{array}{c}\text { FAC3 Batch } \\
\text { Column }\end{array}$} & $\mathrm{B} 2002$ & 1577 & 72 & 73 & 0.22 \\
\cline { 2 - 6 } & $\mathrm{C} 2165$ & 3926 & 78 & 65 & 0.29 \\
\hline $\begin{array}{c}\text { FAC4 Batch } \\
\text { Column }\end{array}$ & 2002 & 1613 & 74 & 79 & 0.20 \\
\cline { 2 - 6 } & 2661 & 5210 & 82 & 66 & 0.22 \\
\hline $\begin{array}{c}\text { FAC5 Batch } \\
\text { Column }\end{array}$ & 3007 & 1653 & 83 & 79 & 0.21 \\
\cline { 2 - 6 } & 3104 & 5382 & 86 & 67 & 0.19 \\
\hline
\end{tabular}

Table 2 shows resistance factors reported for both batch and column adsorption of BOD and COD of VOIE using $1 \mathrm{~g}$ of each PFAC. Lowest values for both \% BOD (61) and \% COD (35) were recorded for $\mathrm{FAC}_{2}$. Though $\mathrm{FAC}_{5}$ had similar \% COD (79) as $\mathrm{FAC}_{1}$ and $\mathrm{FAC}_{3}$, it showed highest values of $83 \%$ and $79 \%$ respectively.

All other values of percent COD removal had no significant difference from each other at $\mathrm{P}>0.05$. The $\triangle \mathrm{BOD}$ and $\triangle \mathrm{COD}$ were significantly different, though the trend was the similar; the $\triangle \mathrm{COD}$ was higher than $\triangle \mathrm{BOD}$ as expected except for $\mathrm{FAC}_{5}$. The $\mathrm{BOD} / \mathrm{COD}$ ratio ranged from $\mathrm{FAC}_{4}(0.20)$ to $\mathrm{FAC}_{2}(0.29)$, was basically the same and lower than unity. This means that the VOIE treated with PFAC in batch was more biogradable.

When PFACs were used for reducing BOD and COD of VOIE in column process results (table 2) showed that $\triangle \mathrm{BOD}$ ranged from $\mathrm{FAC}_{2}$ (1180) to $\mathrm{FAC}_{5}$ (3104) where as $\triangle \mathrm{COD}$ ranged from $\mathrm{FAC}_{5}(5382)$ to $\mathrm{FAC}_{2}(1270)$. Percent reduction in $\mathrm{BOD}$ ranged from $\mathrm{FAC}_{1}(59)$ to $\mathrm{FAC}_{5}(86)$.

The increasing order for preferring to reduce $\mathrm{BOD}$ in a column using PFACs was as follows: $\mathrm{FAC}_{2}>\mathrm{FAC}_{1}>\mathrm{FAC}_{3}>\mathrm{FAC}_{4}>\mathrm{FAC}_{5}$. Except for $\mathrm{FAC}_{5}(0.19)$, values for BOD/COD for column adsorption using PFACs showed a narrow range. These values are highly recommended for effluent by EHSG standards prior to discharge. 
Table 3. Physicochemical properties of effluent after adsorption PFAC in a batch system.

\begin{tabular}{|c|c|c|c|c|c|}
\hline & FAC 1 & EAC 2 & FAC 3 & FAC 4 & FAC 5 \\
\hline $\mathrm{pH}$ & $8.17 \pm 0.25$ & $8.10 \pm 0.30$ & $6.70 \pm 0.26$ & $6.80 \pm 0.10$ & $7.07 \pm 0.25$ \\
\hline $\begin{array}{c}\text { Temp }{ }^{\circ} \mathrm{C} \\
\mathrm{Cond} \\
\mu \mathrm{S} / \mathrm{cm}\end{array}$ & $26.33 \pm 1.15$ & $26.00 \pm 1.00$ & $26.00 \pm 1.00$ & $24.33 \pm 1.52$ & $25.67 \pm 0.57$ \\
\hline $\mathrm{TDS} \mathrm{mg} / \mathrm{l}$ & $310.00 \pm 9.00$ & $305.67 \pm 6.03$ & $297 \pm 9.02$ & $319 \pm 15.95$ & $238.67 \pm 6.51$ \\
\hline $\mathrm{D} . \mathrm{O} \mathrm{mg} / \mathrm{l}$ & $6.43 \pm 0.12$ & $6.70 \pm 0.36$ & $5.80 \pm 0.20$ & $6.63 \pm 0.32$ & $7.23 \pm 0.35$ \\
\hline $\mathrm{BOD} \mathrm{mg} / \mathrm{l}$ & $8.60 \pm 0.30$ & $7.33 \pm 0.15$ & $7.78 \pm 0.42$ & $8.13 \pm 0.87$ & $6.03 \pm 0.21$ \\
\hline $\mathrm{COD} \mathrm{mg} / \mathrm{l}$ & $15.07 \pm 0.70$ & $11.87 \pm 0.65$ & $15.77 \pm 0.75$ & $16.13 \pm 0.61$ & $16.53 \pm 0.65$ \\
\hline $\mathrm{BOD} / \mathrm{COD}$ & $0.51 \pm 0.03$ & $0.62 \pm 0.07$ & $0.44 \pm 0.05$ & $0.48 \pm 0.55$ & $0.34 \pm 0.03$ \\
\hline
\end{tabular}

Results of $\mathrm{pH}$ ranged from $\mathrm{FAC}_{5}(6.5 \pm 0.2)$ in a batch experiment to $\mathrm{FAC}_{4}(9.7 \pm-0.5)$ in a batch It was observed that $\mathrm{pH}$ of effluence varied in batch and column experiment for the same AC sample. On the other hand temperature was generally uniform for most samples in batch and column experiments. The fluctuation in $\mathrm{pH}$ was reflected in conductivity measurements. This may be explained by proposing that the washing of the ACs may not have been proper and so ionisable substances as impurities may cause the changes in $\mathrm{pH}$ and conductivity. These values are however within acceptable limits for effluents from vegetable oil industry [26]. TDS in mg/l ranged from $\mathrm{FAC}_{1}(216 \pm 12)$ to $\mathrm{FAC}_{2}$ and $\mathrm{FAC}_{3}(320 \pm 10)$ dissolved oxygen raged from $\mathrm{FAC}_{2}(30 \pm 5)$ to $\mathrm{FAC} 1(40 \pm 4.0)$ while the BOD values ranged from FAC4 $(508 \pm 3.0)$ to $\mathrm{FAC}_{1}(840 \pm 20)$ while COD ranged from $\mathrm{FAC}_{2}(2100 \pm 10)$ to $\mathrm{FAC}_{1}$ $(3423 \pm 33)$. The biodegradability factor $\mathrm{BOD} / \mathrm{COD}$ ratio was generally low and ranged from $\mathrm{FAC}_{4}(0.19)$ to $\mathrm{FAC}_{2}(0.29)$.

Results reveal that batch experiments enhance the biodegradability of the effluents batch experiment values for biodegradability were in increasing order:

$\mathrm{FAC}_{4}<\mathrm{FAC}_{5}<\mathrm{FAC}_{3}<\mathrm{FAC}_{1}<\mathrm{FAC}_{2}$

while column experiment showed the order order:

$\mathrm{FAC}_{5}<\mathrm{FAC}_{4}<\mathrm{FAC}_{3}<\mathrm{FAC}_{2}<\mathrm{FAC}_{1}$.

From results presented here batch adsorption showed better reduction in organic load of effluents using PFAC.

This could be associated with good development of internal surface usually observed in chemically prepared activated carbon [27]. The batch system therefore could be a better technique for reducing organic pollutants of vegetable oil industry effluents. 


\section{3. Factors affecting adsorption of BOD and COD from vegetable oil industry effluents}

Three samples of the industrial effluent were collected once a week for five weeks and preserved at $4{ }^{\circ} \mathrm{C}$ and then analysed the next day. For contact time, carbon dose, $\mathrm{pH}$ and temperature.

\section{4. Contact time variation with BOD and COD}

Figure 1 shows that there was a general reduction of BOD effluents with time for all five PFAC while $\mathrm{FAC}_{1} \mathrm{FAC}_{2}$ and $\mathrm{FAC}_{4}$ showed comparable reduction in $\mathrm{BOD}, \mathrm{FAC}_{3}$ and $\mathrm{FAC}_{5}$ were different with a higher reduction. The order of reduction of BOD as a function of contact time is a follows: $\mathrm{FAC}_{5}>\mathrm{FAC}_{3}>\mathrm{FAC}_{4}>\mathrm{FAC}_{2}>\mathrm{FAC}_{1}$.
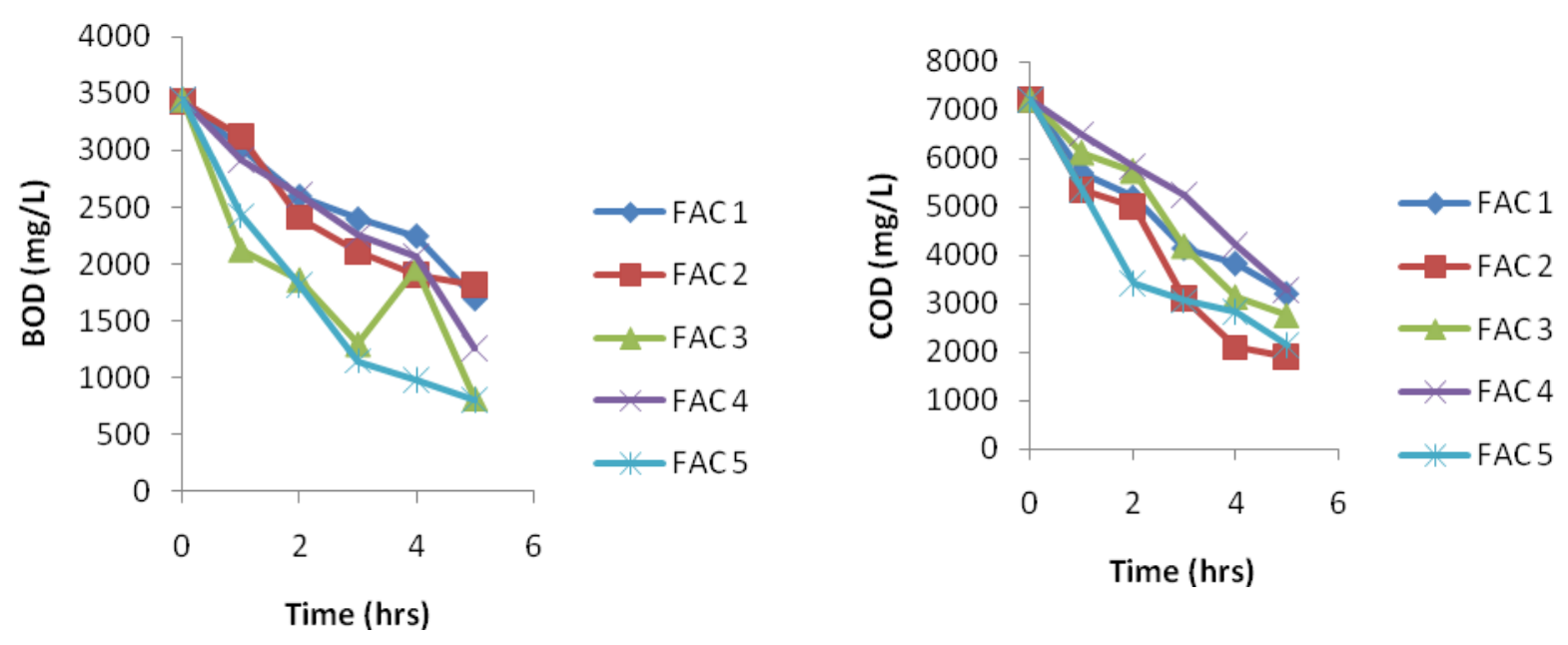

Figure 1. Effect of contact time on BOD of VOIE in a batch system treated with $1 \mathrm{~g}$ of PFAC.

There was an anomalous behavior observed for $\mathrm{FAC}_{3}$ at contact time of 4 hours the BOD seem to increase before dropping to a value close to that for $\mathrm{FAC}_{5}$. There was fast reduction at initial stage i.e. over 1 to 2 hours but the reduction in BOD slowed drastically by the end of the $5^{\text {th }}$ hours. The fifth hours may correspond to equilibrium time. [28] explains that this may be due to the fact that initially a large number of vacant sites were available for adsorption which progressively became smaller with time. Figure 2 shows the effect of contact time on COD for $1 \mathrm{gs}$ of FFAC in a batch system in terms of COD. FAC $\mathrm{FAC}_{3}$ and $\mathrm{FAC}_{4}$ showed similar trend while $\mathrm{FAC}_{2}$ and $\mathrm{FAC}_{5}$ were closer both at initial stage and at the end of five hours as expected occurred at the initial stages most of PFACs. Less reduction from initial stage to the last stage with $\mathrm{FAC}_{4}$, while $\mathrm{FAC}_{2}$ showed a higher reduction at the end of the fifth hour. The decreasing order of COD removal using $2 \mathrm{gs}$ of PFAC in a batch with respect to contact time as follows: $\mathrm{FAC}_{2}>\mathrm{FAC}_{5}>\mathrm{FAC}_{3}>\mathrm{F} \mathrm{AC}_{1}>\mathrm{FAC}_{4}$.

The effect of BOD variation with contact time using 1 gs of PFAC is shown graphically in Figure 4.13. $\mathrm{FAC}_{3}$ and $\mathrm{FAC}_{5}$ showed higher reduction in BOD both at initial stage and final stage. While $\mathrm{FAC}_{1}$ and $\mathrm{FAC}_{2}$ showed anomalies; but it should be noted that all five PFACs showed similar reduction in BOD at the initial stage and again, [28] suggested an explanation to this that more active surfaces available for adsorption at the initial stage and towards the end of the experiment- longer contact time, the active sites are consumed and are less available $\mathrm{COD}$ reduced steadily with time for $\mathrm{FAC}_{3}$ and $\mathrm{FAC}_{5}$ which shows higher values of cod. $\mathrm{FAC}_{1}$ and $\mathrm{FAC}_{2}$ showed less reduction of COD even higher contact time. At five hours 
$\mathrm{FAC}_{1}$ and $\mathrm{FAC}_{2}$ had very close COD reduction which are lower than for $\mathrm{FAC}_{3}, \mathrm{FAC}_{4}$ and $\mathrm{FAC}_{5}$. A lower curve shows better reduction of COD with higher gradient representing good adsorption. The decreasing order of $\mathrm{COD}$ with contact time when $1 \mathrm{~g}$ of PFAC is used for adsorption is as follows: $\mathrm{FAC}_{3}>\mathrm{FAC}_{5}>\mathrm{FAC}_{4}>\mathrm{FAC}_{2}$ and $\mathrm{FAC}_{1}$.
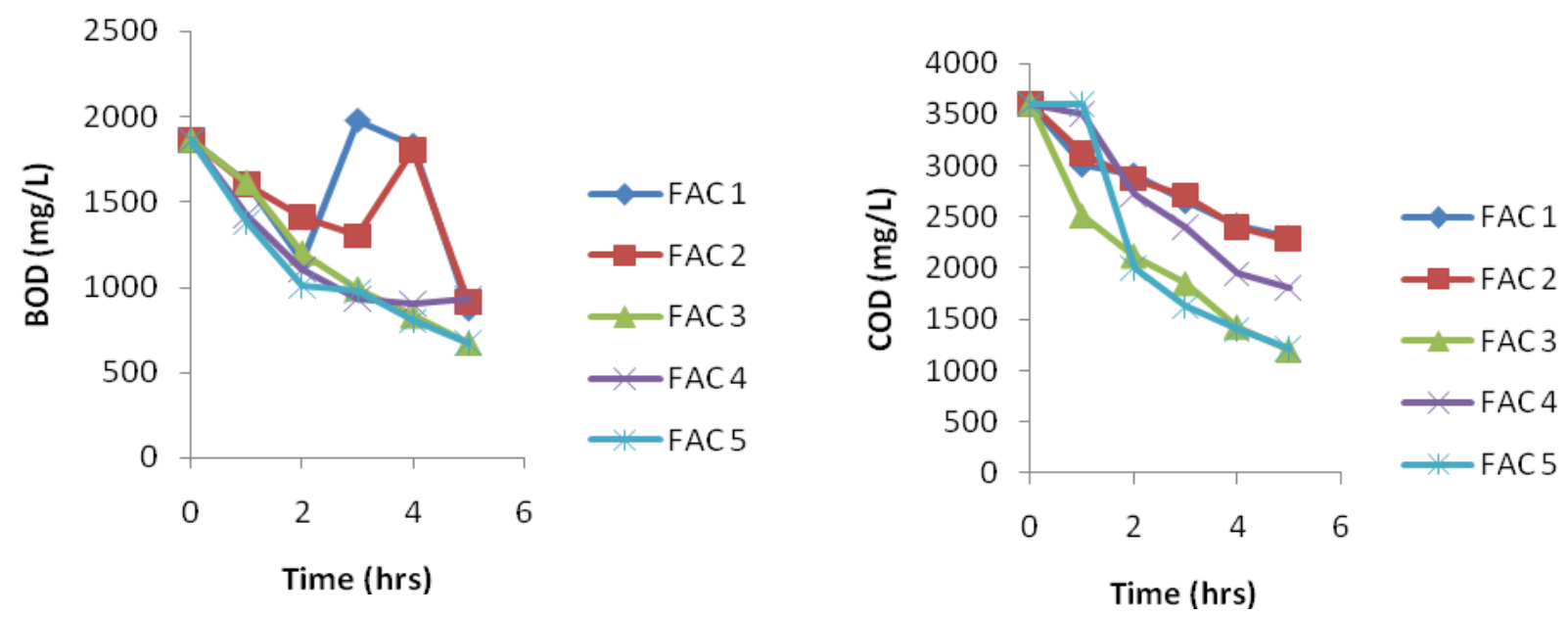

Figure 3. Effect of contact time on BOD and COD of effluent treated in a column.
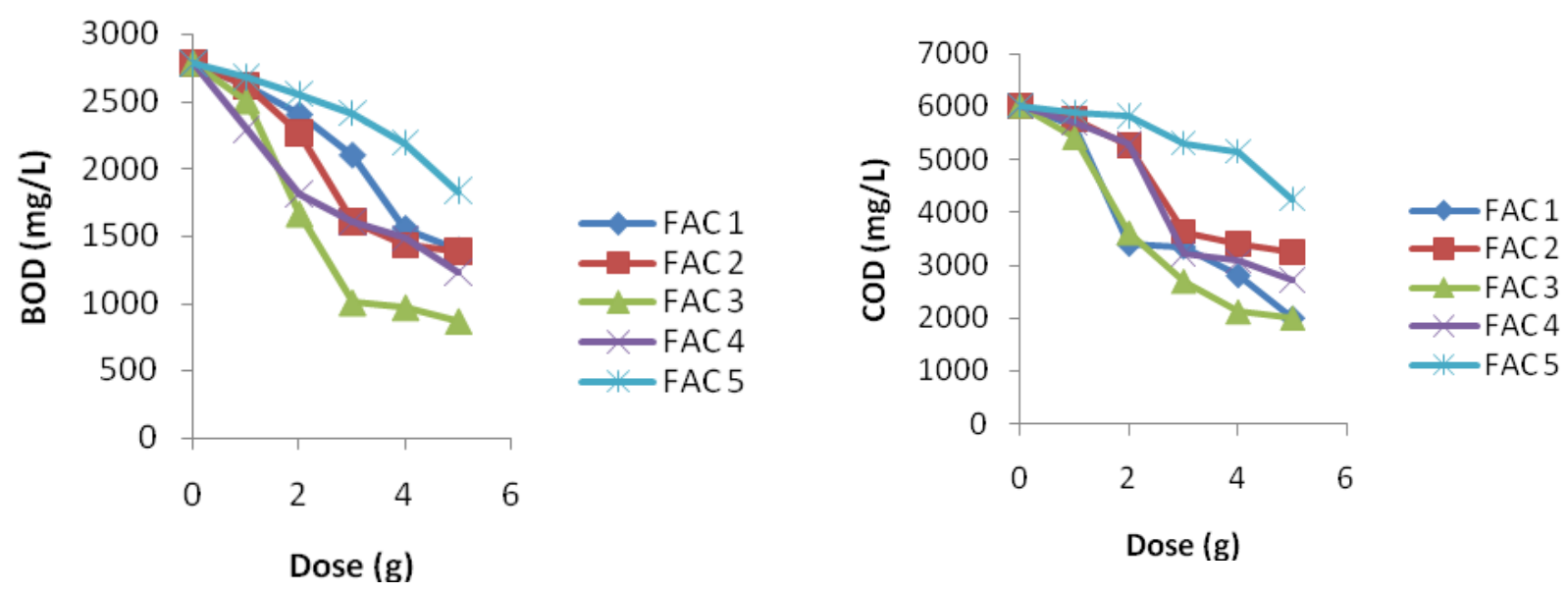

Figure 4. Variation of BOD and COD with Carbon does using PFAC in a batch system.

Figure 4 shows the effect of varying carbon dose on BOD in a batch process. Four PFAC showed poor adsorption while $\mathrm{FAC}_{3}$ showed better adsorption; the adsorption was similar for all PFACs. Higher Carbon dose showed good adsorption. This can be attributed to increase in adsorption surfaces provided by increasing amount of AC. The order of preferred adsorption as Carbon dose of $\mathrm{FAC}_{5}$ being increased was $\mathrm{FAC}_{3}>\mathrm{FAC}_{4}>\mathrm{FAC}_{2}>\mathrm{FAC}_{1}>$ $\mathrm{FAC}_{5}$. Increasing Carbon dose from $3 \mathrm{~g}$ to $5 \mathrm{~g}$ did not have any effect on $\mathrm{FAC}_{5}$ even though $\mathrm{FAC}_{5}$ showed the best adsorption whereas increase carbon dose from $3 \mathrm{~g}$ to $5 \mathrm{~g}$ for $\mathrm{FAC}_{1}$ showed good reduction in BOD. After carbon dose of $4 \mathrm{~g}$ there was no much change in BOD of effluents for most PFAC. 
Figure 5 represent the effects of Carbon dose variation on COD of effluent in a batch. $\mathrm{FAC}_{3}$ and $\mathrm{FAC}_{1}$ showed better adsorption leading to reduction of COD than all other $\mathrm{AC}$ sample preferred by physical activation. The order of preferred $\mathrm{AC}$ performance: $\mathrm{FAC}_{3}>$ $\mathrm{FAC}_{1}>\mathrm{FAC}_{4}>\mathrm{FAC}_{2}>\mathrm{FAC}_{5}$. At all carbon doses, except at $2 \mathrm{~g}, \mathrm{FAC}_{3}$ showed excellent reduction of $\mathrm{COD}$ while $\mathrm{FAC}_{5}$ was poorest at all carbon dose.
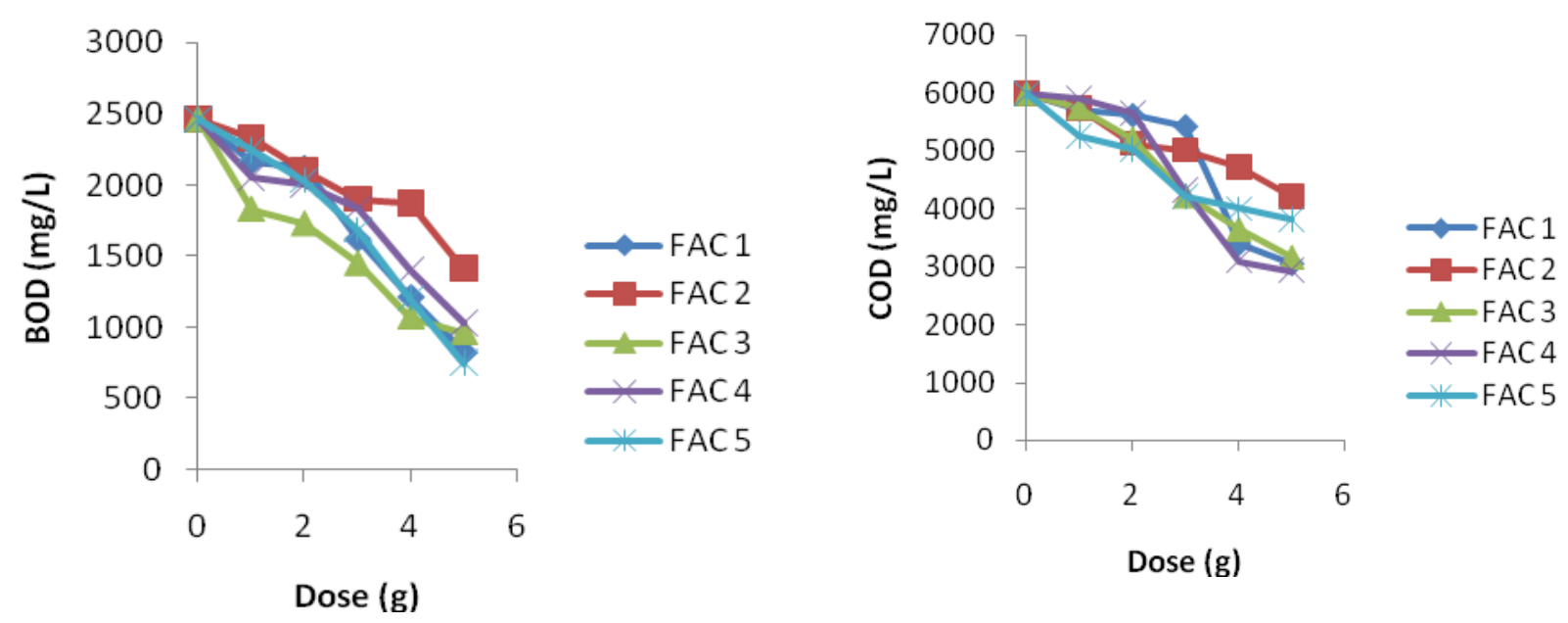

Figure 5. Carbon dose experiment of BOD and COD using PFAC in a column process.

Figure 5 shows the effect of varying Carbon dose on BOD of effluents using PFAC in a column. $\mathrm{FAC}_{5}$ exhibited highest removal of BOD than all others while $\mathrm{FAC}_{1}$ was lowest. The reduction on BOD was essentially similar for all PFAC. However the order of decreasing preference of PFAC towards reducing BOD in a column with respect to carbon doses was as follows:

$\mathrm{FAC}_{5}>\mathrm{FAC}_{1}>\mathrm{FAC}_{3}>\mathrm{FAC}_{4}>\mathrm{FAC}_{2}$.

Generally, as carbon dose increases the number of sorption sites available for organic pollutants increases due to increase in surface area. Several researches have reported this principle [29-31].

Figure 6 shows that at lower carbon dose (1-2 g), the BOD showed little variation for most PFAC but as from Carbon dose of 2 to $4 \mathrm{~g}$ there is a sharp decrease in BOD for FAC1 and FAC4 while there is steady decrease of BOD for FAC3 and FAC2 whereas FAC5 showed good BOD reduction at lower values of 1-2 g Carbon dose.

\section{5. $\mathrm{pH}$ variation with $\mathrm{BOD}$ and COD using $1 \mathrm{~g}$ of pfac in batch experiment}

Figure 6 represents plots of BOD versus $\mathrm{pH}$ for various CFAC in a batch system. The curves shows that reduction of BOD was steady as $\mathrm{pH}$ increased from 2 to 9 but starts to level off for $\mathrm{FAC}_{3}, \mathrm{FAC}_{1}$, and $\mathrm{FAC}_{5}$, while for $\mathrm{FAC}_{2}$ and $\mathrm{FAC}_{4}$ the decrease in $\mathrm{pH}$ continued steadily till $\mathrm{pH} 11$. The order of decreasing $\mathrm{BOD}$ reduction with respect to $\mathrm{pH}$ varying for all PFAC using in batch process was: $\mathrm{FAC}_{3}>\mathrm{FAC}_{1}>\mathrm{FAC}_{2}>\mathrm{FAC}_{5}>\mathrm{FAC}_{4}$. It should be noted steeper gradients for BOD against $\mathrm{pH}$ curves were observed at $\mathrm{pH}$ range of 5 to 8 implying that better reduction of BOD was favored within this $\mathrm{pH}$ range. Figure 8 shows the variation of COD with $\mathrm{pH}$ for $1 \mathrm{~g}$ of PFAC in a batch system the curves showed that $\mathrm{FAC}_{3}$ and $\mathrm{FAC}_{4}$ had the best reduction in COD of VOIE at $\mathrm{pH}=11$ while $\mathrm{FAC}_{1}$ was lowest in reducing COD 
of VOIE in a batch at some $\mathrm{pH}=11$ using $2 \mathrm{~g}$ of PFAC. At lower $\mathrm{pH}$ (2-6), $\mathrm{FAC}_{1}$ was the best adsorbent followed by $\mathrm{FAC}_{3}$. At lower $\mathrm{pH}$ values the preference for $2 \mathrm{~g}$ PFAC in a batch was: $\mathrm{FAC}_{1}>\mathrm{FAC}_{3}>\mathrm{FAC}_{4}>\mathrm{FAC}_{5}>\mathrm{FAC}_{2}$, whereas at higher $\mathrm{pH}$ values (8-11) the order was observed to be:

$\mathrm{FAC}_{3}>\mathrm{FAC}_{4}>\mathrm{FAC}_{1}>\mathrm{FAC}_{2}>\mathrm{FAC}_{5}$.
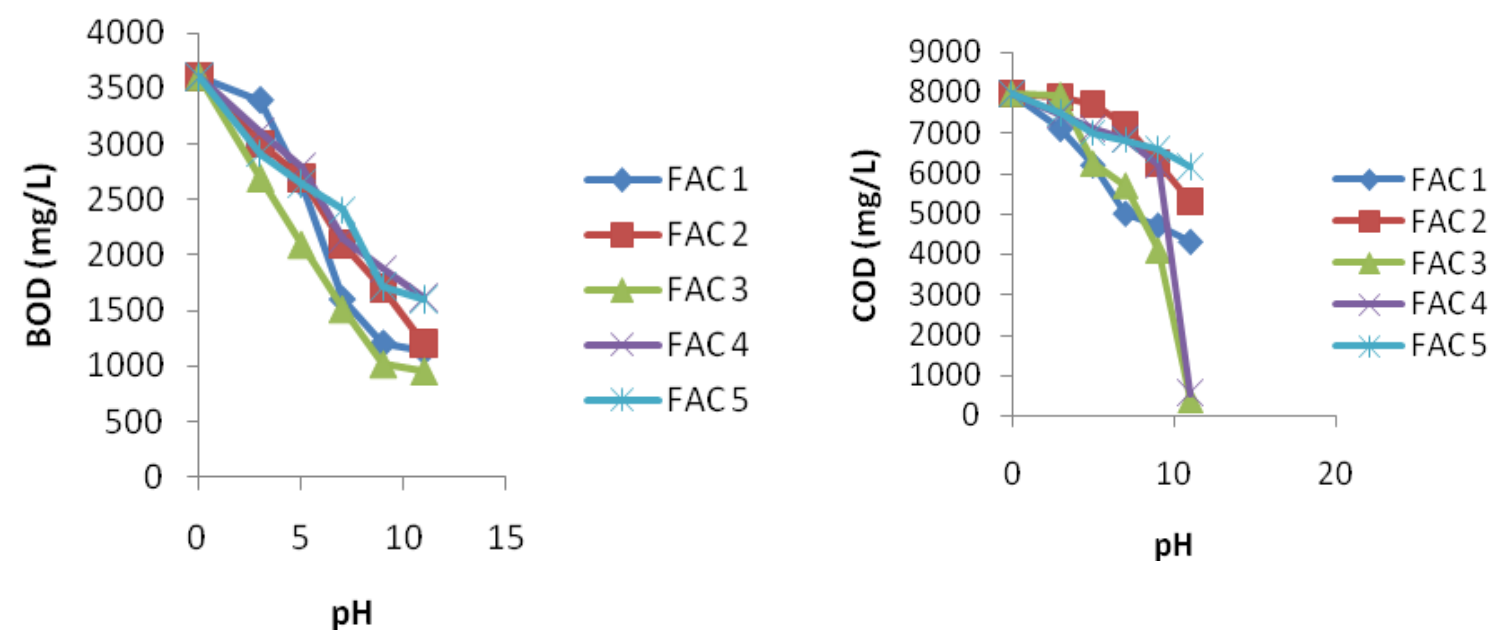

Figure 6. Variation of BOD with $\mathrm{pH}$ with $1 \mathrm{~g}$ of PFAC in a batch process.

\section{6. $\mathrm{pH}$ variation with bod using $1 \mathrm{~g}$ of pfac in column experiment}
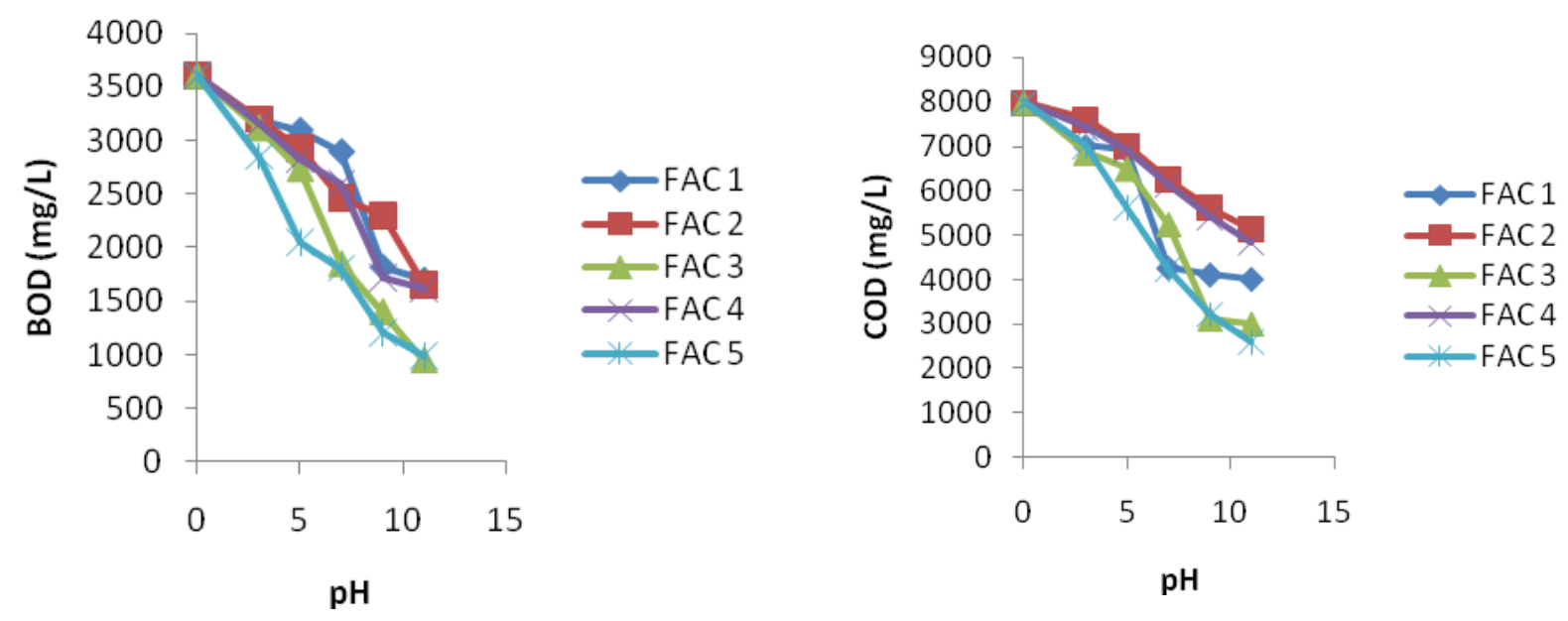

Figure 9. Variation of BODand COD with $\mathrm{pH}$ for $1 \mathrm{~g}$ of PFAC in a column process.

Figure 9 represent the variation of BOD of VOIE as a function of $\mathrm{pH}$ using $1 \mathrm{~g}$ PFAC in a column process. At lower $\mathrm{pH}$ values (1-4), $\mathrm{FAC}_{1}, \mathrm{FAC}_{2}$ and $\mathrm{FAC}_{3}$ show similar behavior, which is reduction of $\mathrm{BOD}$, was almost same but at high $\mathrm{pH}$ values $(5-11)$ the reduction in BOD was same for $\mathrm{FAC}_{1} \mathrm{FAC}_{2}$ and $\mathrm{FAC}_{4}$ and same for $\mathrm{FAC}_{3}$ and $\mathrm{FAC}_{5}$ with $\mathrm{FAC}_{3}$ and 
$\mathrm{FAC}_{5}$ showing better reduction than the other three. There was preference for reduction of $\mathrm{BOD}$ at higher temperatures while at lower temperature the order of preference was: $\mathrm{FAC}_{5}>$ $\mathrm{FAC}_{3}>\mathrm{FAC}_{4}>\mathrm{FAC}_{2}>\mathrm{FAC}_{1}$. Higher temperatures favored BOD reduction of VOIE using physically prepared activated carbon.

The variation of COD with $\mathrm{pH}$ for $1 \mathrm{~g}$ of PFAC in a column is shown in figure 4.25. The reduction of $\mathrm{COD}$ at lower $\mathrm{pH}$ is smaller than for the reduction at higher $\mathrm{pH}$ values. There is however a division of reduction potentials of PFAC into three groups. At higher $\mathrm{pH}$ values, $\mathrm{FAC}_{4}$ and $\mathrm{FAC}_{2}$ showing lower reducing tendencies while $\mathrm{FAC}_{3}$ and $\mathrm{FAC}_{5}$ were higher, $\mathrm{FACl} 1$ was alone as on intermediate. The general preference for reduction of COD for varying $\mathrm{pH}$ values in a column experiment using $\mathrm{PFAC}$ was: $\mathrm{FAC}_{5}>\mathrm{FAC}_{3}>\mathrm{FAC}_{1}>\mathrm{FAC}_{4}>$ $\mathrm{FAC}_{2}$.
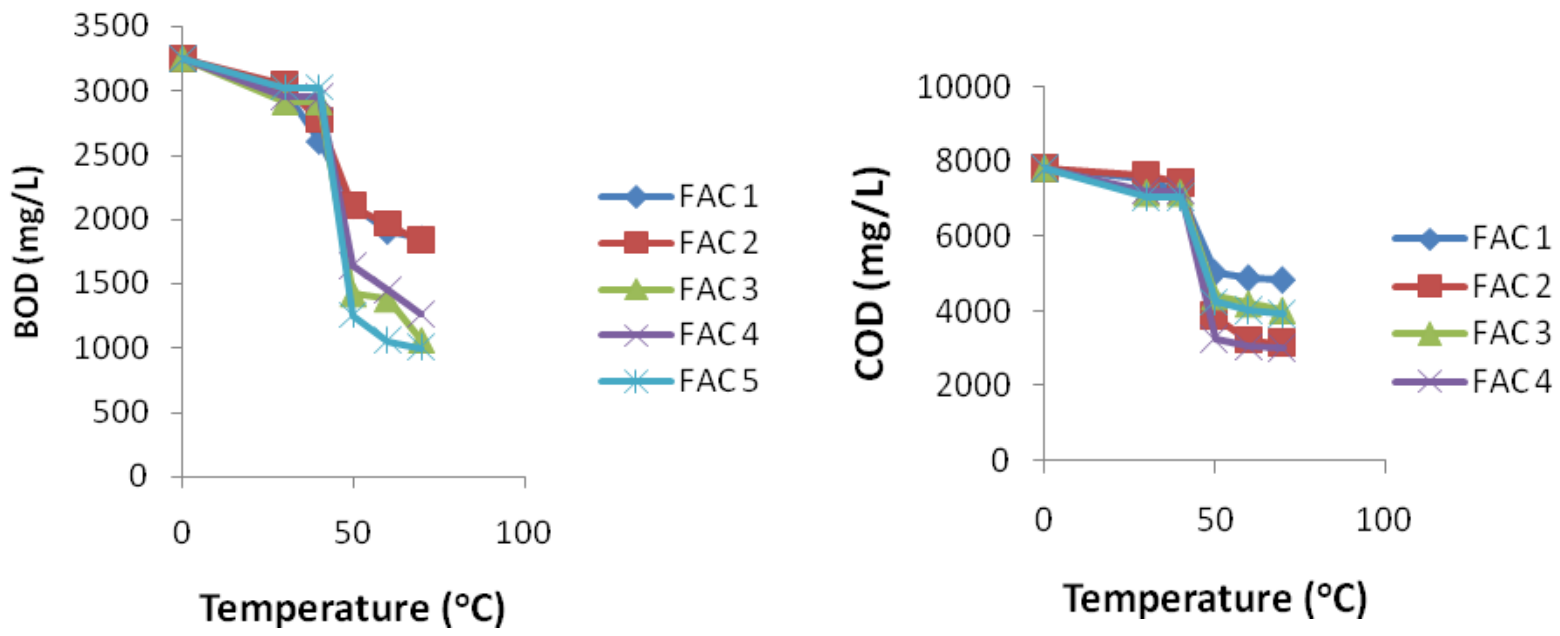

Figure 10. Variation of BOD with temperature using $1 \mathrm{~g}$ of PFAC in a batch process.

Figure 10 shows BOD reduction of VOIE as a function of temperature for $1 \mathrm{~g}$ of PFAC in a batch system. At lower temperatures $10-30^{\circ} \mathrm{C}$, there was very little reduction in BOD. All values of BOD reduction were very similar at this range. However at above $40^{\circ} \mathrm{C}$, there was a drastic reduction in BOD which again slowed down for all five PFAC above $50{ }^{\circ} \mathrm{C}$ at higher temperatures, $\mathrm{FAC}_{2}$ and $\mathrm{FAC}_{1}$ showed similar behavior. $\mathrm{FAC}_{5}$ and $\mathrm{FAC}_{3}$ behaved similar as well while $\mathrm{FAC}_{4}$ was intermediate. The order of preference of reduction of BOD using $1 \mathrm{~g}$ of PFAC and varying $\mathrm{pH}$ showed the following orde:

$\mathrm{FAC}_{5}>\mathrm{FAC}_{3}>\mathrm{FAC}_{4}>\mathrm{FAC}_{2}>\mathrm{FAC}_{1}$.

Figure 11 shows the effect of varying temperature on COD of VOIE using $1 \mathrm{~g}$ of PFAC in a batch. The curves behaved similar to those in Figure 4.30 at lower temperature, the reduction in COD was minimal whereas at higher temperature, a huge reduction in COD was observed. Above $50{ }^{\circ} \mathrm{C}$, the PFAC were divided into three groups with $\mathrm{FAC}_{1}$ in the first group showing lowest reduction in $\mathrm{COD} ; \mathrm{FAC}_{3}$ and $\mathrm{FAC}_{5}$ in the second group showing intermediate reduction and lastly, group three with $\mathrm{FAC}_{4}$ and $\mathrm{FAC}_{2}$ showing highest reduction in COD. 


\section{7. Temperature variation with BOD using $1 \mathrm{~g}$ of pfac in column experiment}
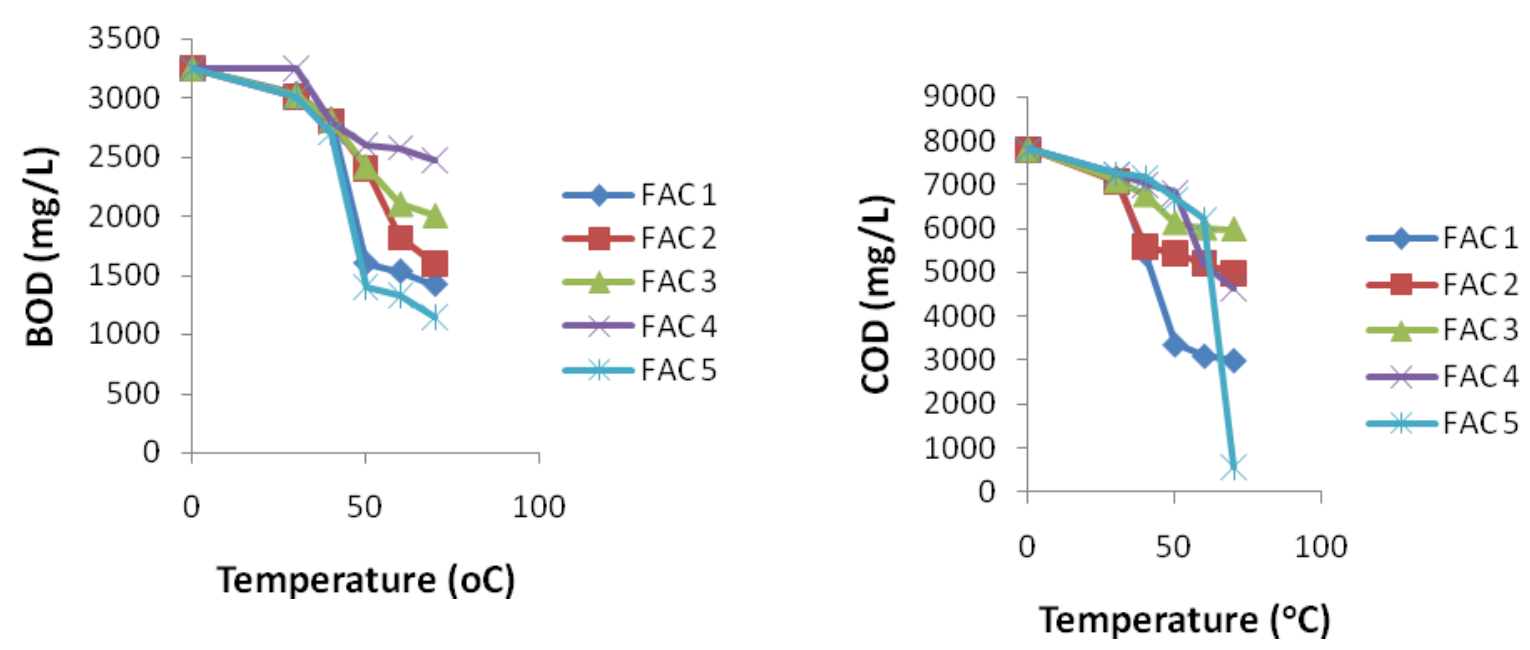

Figure 12. Variation of BOD and COD with temperature using $1 \mathrm{~g}$ of PFAC in a column process.

Figure 12 represents plots of BOD of VOIE against temperature using $1 \mathrm{~g}$ of PFAC in a column experiment. the graphs showed that $\mathrm{FAC}_{3}, \mathrm{FAC}_{2}, \mathrm{FAC}_{5}$ and $\mathrm{FAC}_{1}$ were better in BOD reduction than $\mathrm{FAC}_{4}$ at lower temperature $\left(10-30{ }^{\circ} \mathrm{C}\right)$. Above $40{ }^{\circ} \mathrm{C}$ there was an appreciable reduction by all PFAC. The order from highest to least reduction of BOD at higher temperatures is:

$\mathrm{FAC}_{5}>\mathrm{FAC}_{1}>\mathrm{FAC}_{2}>\mathrm{FAC}_{3}>\mathrm{FAC}_{4}$.

$\mathrm{FAC}_{4}$ showed lower reduction at both lower and higher temperatures. Figure 13 shows a drastic reduction of COD between $60{ }^{\circ} \mathrm{C}$ to $70{ }^{\circ} \mathrm{C}$ for $\mathrm{FAC}_{5}$. This is anomalous as most carbons have shown drastic reduction of COD at temperatures between $40{ }^{\circ} \mathrm{C}$ to $50^{\circ} \mathrm{C}$. Figure 13 equally shows that at lower temperatures $10^{\circ} \mathrm{C}$ to $30^{\circ} \mathrm{C}$, all PFAC had insignificant reduction in COD. The order of reduction of COD at the temperatures above $40^{\circ} \mathrm{C}$ was:

$$
\mathrm{FAC}_{5}>\mathrm{FAC}_{1}>\mathrm{FAC}_{4}>\mathrm{FAC}_{3}>\mathrm{FAC}_{2} \text {. }
$$

There was however poor performance by $\mathrm{FAC}_{1}$ to $\mathrm{FAC}_{4}$ in reducing COD of VOIE using $1 \mathrm{~g}$ of PFAC in a column process.

\section{CONCLUSION}

All adsorbents showed good BOD and COD reduction though carbons prepared at lower temperatures had poor adsorption capacities. Values of resistance factors were higher for BOD than COD indicating that PFACs could have a positive effect on biodegradability of the effluents. Batch adsorption gave better BOD and COD reduction than column absorption. The maximum BOD reductions were obtained for carbons prepared at higher temperatures in the case of higher carbon doses employed in longer adsorption times. However factors 
influencing adsorption of BOD and COD were generally difficult to streamline thus requiring more in depth studies.

\section{ACKNOWLEDGEMENTS}

This work is completed as part of $\mathrm{PhD}$ thesis in the department of Pure and industrial chemistry, University of Port Harcourt. We thank members of the Research in Analytical Chemistry and Environment Pollution Studies (RACEPS) and Doctoral students of Professor M. Horsfall Jnr and Professor A. I Spiff. We express deep gratitude to the Director; Centre for Energy Research University of Nigeria Nsukka, for the use of certain scientific instruments, the expertise of Mr. Ofomata Anthony Chibuzo the chemical analyst, and Engineer Clement of Federal Environmental Laboratory, Imo State.

\section{References}

[1] Verla A. W., Verla E. N., Adowei P., Briggs O. A., Horsfall Jnr. M., International Letters of Chemistry, Physics and Astronomy 14(2) (2014) 179-189.

[2] Kim Y., Kim C., Choi I., Rengaraj S., Yi J., Environmental Science and Technology 38 (2004) 924-931.

[3] USEPA, EPA/600/R 93/089, United States Environmental Protection Agency, 1993.

[4] Ho Y.S., McKay G., Trans. IchemE 76 (1998) 183-191.

[5] Pendyal B., Johns M.M., Marshall W.E., Ahmedna M., Rao R.M., Bioresource Technol. 69 (1999) 45-51.

[5] Azbar N.Y., Process Biochemsitry 39(7) (2008) 869-875.

[7] A.O Ekpete. M. Horsfall Jr., T. Tarawou, Journal of Engineering and Applied Sciences 5(9) (2010) 3947.

[8] Faust S.D., Aly O.M. (1987). Adsorption Process for Water Treatment. Butterworths Publishers, Stoneham.

[9] Hamdaoui E. Naffrechoux, Journal of Hazardous Substances 147 (2007) 381-394.

[10] McKay G., Blair H., Gardiner J.R., Journal of Applied Polymer Science 28 (1989) 1499-1544.

[11] Kim Y.S., Quereshi T.I., Min K.S., Environmental Technology 24(126) (2003) 9-1276.

[12] Gaydardzhiev S., Karthikeyan J., Ay P., Environmental Technology 27 (2006) 193-199.

[13] Khadija Q., Inamullah B., Rafique K., Abdul K. A., International Journal of Chemical and Biomolecular Engineering 1 (2008) 3.

[14] Chilton N.W., Marshall R.M., Rao R.R., Bansode J.N., Portier R.J. (2003). Granular Activated Carbons from Agricultural Byproducts: Process Description and Estimated Cost of Production: Louisiana State University Agricultural Center (Research and Extension: Baton Rouge, LA. August 2003. Bulletin Number 881.

[15] P. Atkins, J Paula Atkin's physical chemistry. Oxford University Press, (2008) 916-917.

[16] Shah B.A, V.A. Shah, H.D. Patel, Int. J. of waste management 7(1/2) (2011) 192-208.

[17] Ahmad A.A., Hameed B.H., J. Hazard. Mater. 175 (2010) 298-303. 
[18] Sarkar M., Datta P.K., Sarkar A.R., J. Ind. Pollut. Control 17 (2001) 179-190.

[19] Ardizzone S., Gabrielli G., Lazzari P., Colloids and Surfaces A 76 (1993) 149.

[20] Verla A. W., M. Horsfall (Jnr), E.N. Verla, A.I. Spiff, O.A. Ekpeto, Asian Journal of Science 1(2) (2012) 1-50.

[21] Toles C.A., Johns M.M., Marshall W.E., J. Chem. Technol. Biotechnol 71 (1998) 131-140.

[22] M .Horsfall Jnr., A.I. Spiff, J. Chemistry and Biodiversity 2 (2005) 1-12.

[23] Chakroborty S., Basu J.K., De, S. Dasgupta S., Industrial and Engineering Chemistry Research 45 (2006) 4732-4741.

[24] Abdul R. Yacob Z., Abdul M., Ratna S., Dewi D., Vincinisvarri I., The Malaysian Journal of Analytical Sciences 1(1) (2008) 12-18.

[25] V.K. Gupta. S. Srivastava, R. Tyagi. Water Resources 34(5) (2000) 1543-1550.

[26] Weber T.W.. Chakraborti R.K., American Institute of Chemical Engineers Journal 20 (1974) 228-238.

[27] Kinigoma B. S., M. Horsfall Jnr., American Journal of Engineering Research 03(06) (2014) 247-265.

[28] Ojha K., Pradhan C., Samanta A.N., Bull. Mater. Sci. 27 (2004) 555-564.

[29] Peters M., Timmerhaus K. (1991). Plant Design and Economics for Chemical Engineers. McGraw-Hill: New York, NY.

[30] Schwarz J.A., Noh J.S., Carbon 28 (1990) 675-682.

[31] F.T. Ademiluyi, S.A. Amadi, N.J. Amakama, Journal of Applied Science and Envirionmental Management 13(3) (2009) 39-47.

[32] Umesh K.G., Dhirag S., Electronic Journal of Environmental Agriculture and Food Chemistry (2005) 1579-4377. 